\section{The Influence of Climate on Fruit Shape of Four Low-chill Peach Cultivars}

\author{
Todd W. Wert ${ }^{1}$, Jeffrey G. Williamson ${ }^{2}$, José X. Chaparro, \\ and E. Paul Miller \\ Department of Horticultural Sciences, University of Florida, 2113 Fifield \\ Hall, Hull Road, Gainesville, FL 32611-0690
}

\section{Robert E. Rouse \\ Southwest Florida Research and Extension Center, University of Florida, Immokalee, FL 34142}

Additional index words. Prunus persica, winter chilling requirement, subtropical, suture bulge, blossom end, temperature, blossom

\begin{abstract}
Fruit shape of four low-chill peach [Prunus persica (L.) Batsch] cultivars was evaluated in north-central, central, and southwest Florida. During 2005, measurements were taken at all locations for cheek diameter, suture diameter, and tip protrusion. A suture deformation index was calculated (suture diameter/cheek diameter) to determine suture deformation. Fruit had more protruding tips and suture deformation was more pronounced at the southwest location than at the north-central or central locations. Overall, 'TropicBeauty' had more protruding tips than the other cultivars. It was concluded that warmer temperatures at the southwest location during fruit development affected fruit shape by increasing the incidence of protruding tips and pronounced sutures.
\end{abstract}

The climate where fruit is grown can affect many different aspects of growth and development, including shape. Several reports have been published for fruit other than peaches concerning climatic and temperature effects on fruit shape. In general, higher temperatures tend to produce rounder fruit and lower temperatures tend to produce fruit that are more elongated (Sherman et al., 2003). Fruit elongation of grapefruit, known as "sheepnosing" or "stem end tapering," occurs when plants are exposed to low temperatures (Wutscher, 1976). Other citrus fruit such as oranges and lemons are rounder when grown in warmer areas versus cooler areas (Nauer et al., 1972, 1974). Pepper fruit shape was influenced by temperatures during fruit development, where fruit grown at low night temperatures of $12^{\circ} \mathrm{C}$ were flatter than fruits grown at $18{ }^{\circ} \mathrm{C}$ (Aloni et al., 1999; Rylski and Spigelman, 1982).

The stylar tip of peach fruit can be affected by temperature. More protruding tips have been observed in warmer locations and recessed or flush tips in cooler locations (Salvador et al., 1998; Topp and Sherman, 1989). An analysis of peach fruit quality at 13 locations in Australia indicated that higher average temperatures during the coldest

\footnotetext{
Received for publication 21 Mar. 2007. Accepted for publication 30 July 2007 .

${ }^{1}$ Former graduate student.

${ }^{2}$ To whom reprint requests should be addressed; e-mailjgrw@ufl.edu.
}

month (July) increased tip growth of fruit for most cultivars (Topp and Sherman, 1989).

\section{Materials and Methods}

Three sites were chosen that represented different chilling zones and climates from north-central to south Florida. The northcentral site was located in Archer, FL (Lake fine sand, $29^{\circ} 31^{\prime} 12^{\prime \prime} \mathrm{N}, 82^{\circ} 31^{\prime} 48^{\prime \prime} \mathrm{W}$ ), the second or central location was in Winter Garden, FL (Calendar fine sand, 28 $34^{\prime} 12^{\prime \prime} \mathrm{N}$, $81^{\circ} 34^{\prime} 48^{\prime \prime} \mathrm{W}$ ), and the third or southwest location was in Immokalee, FL (Immokalee fine sand, $\left.26^{\circ} 25^{\prime} 48^{\prime \prime} \mathrm{N}, 81^{\circ} 24^{\prime} 36^{\prime \prime} \mathrm{W}\right)$. The chilling hours (hours below $7.2^{\circ} \mathrm{C}$ ) accumulated at the three sites during the winter of 2004 to 2005 were 402 (north-central Florida), 162 (central Florida) and 125 (southwest Florida). Four low-chill peach cultivars [Flordaglo (150 cu), Flordaprince $(150 \mathrm{cu})$, TropicBeauty (150 cu), and UFGold (200 $\mathrm{cu})$ ] were planted at each site. All cultivars were grafted onto a rootknot nematode-resistant peach rootstock. Trees were planted in Feb. 2002, at all locations using a northsouth row orientation at a distance of $4.6 \mathrm{~m}$ between trees (346 trees/ha) in a randomized complete block design with five replications and single tree plots within each location.

Overhead irrigation was used for frost protection at the north-central site during bloom. Neither the central nor southwest locations received any frost protection. All trees were winter-pruned in early to midJanuary each year. Trees were winter-pruned to an open vase form and headed back to a height of $\approx 2.5 \mathrm{~m}$. The trees were also summer-pruned in early June as needed. Trees at the north-central location received overhead irrigation. At the central and southwest locations, trees were irrigated by microsprinkler emitters.

Weeds were controlled at all locations by maintaining a weed-free strip under the canopy of the trees and between trees. Accepted cultural practices were used for pest and disease management. Fertilizer at the north-central location was applied by hand in three applications: early February, early June, and late September. During 2005, fertilizer applications from an adjacent commercial blueberry field occurred eight times from a mechanical fertilizer spreader on the east side of the trees. These were early February, early March, late March, late May, early July, late July, late August, and early September. When fertilizer was handbroadcast, it was placed primarily under the west half of the tree to compensate for the unequal distribution of fertilizer resulting from the extra applications to the blueberry plot.

Fertilizer application times at the central location were the same as for the northcentral location. However, reclaimed water was used for irrigation at the central location. Total amount of nitrogen $(\mathrm{N})$ applied through reclaimed irrigation water was obtained by calculating an average $\mathrm{N}$ concentration of reclaimed water $\left(0.007 \mathrm{~g} \cdot \mathrm{L}^{-1}\right.$ of $\left.\mathrm{N}\right)$ between July 2005 and Jan. 2006. Additionally, emitter output, line pressure, and the irrigation schedule were used to determine total $\mathrm{N}$ applied, which was calculated at $33.9 \mathrm{~kg} \cdot \mathrm{ha}^{-1}$ per season. Nitrogen fertilizer rates varied among locations. For 2004, these rates were $168 \mathrm{~kg} \cdot \mathrm{ha}^{-1}$ at the north-central location, 103 $\mathrm{kg} \cdot \mathrm{ha}^{-1}$ at the central location, and again 112 $\mathrm{kg} \cdot \mathrm{ha}^{-1}$ at the southwest location.

Each tree was harvested individually and the numbers of both marketable and nonmarketable fruit were recorded. Nonmarketable fruit were delineated as those that were less than $4.5 \mathrm{~cm}$ in diameter, showed signs of wind scaring, catfacing, bacterial spot, insect predation, split pits, deep sutures, or rotten fruit. Fruit were harvested at a firm ripe stage of development; harvest occurred twice each week at all locations. Thirty fruit were selected at random from the marketable fruit from each tree during peak harvest and rated in the field as having recessed, flush, or protruding tips. Additionally, 10 fruit subsamples were selected from the marketable fruit of each tree and measured in two different orientations: cheek to cheek and suture to side opposite suture. The suture deformation index was calculated by dividing the suture to side opposite suture measurement by the cheek to cheek measurement for each cultivar at all locations.

Statistical analyses were preformed using SAS 9.1 (SAS Institute, Cary, NC). For suture deformation index, cultivar-by-location interactions were not significant so only the main effects are reported. Means were determined using PROC GLM and means separations 
among cultivars and locations were by Tukey's honestly significant difference at the $P \leq 0.05$ level.

\section{Results and Discussion}

Average bloom dates for the four cultivars at each location are given in Table 1 . The

Table 1. Bloom dates for four low-chill peach cultivars at three locations in Florida in $2005 .^{\mathrm{z}}$

\begin{tabular}{lrrr}
\hline & \multicolumn{3}{c}{ Location $^{\mathrm{y}}$} \\
\cline { 2 - 4 } Cultivar & North-central & Central & Southwest \\
\hline Flordaprince & 2 Feb. & 24 Feb. & 30 Jan. \\
Flordaglo & 5 Feb. & 28 Feb. & 2 Feb. \\
UFGold & 12 Feb. & 28 Feb. & 1 Feb. \\
TropicBeauty & 2 Feb. & 23 Feb. & 21 Jan. \\
\hline
\end{tabular}

${ }^{\mathrm{z}}$ Date of $50 \%$ to $60 \%$ of full bloom.

${ }^{y}$ Total chill unit accumulation (hours below $7.2^{\circ} \mathrm{C}$ ) at the north-central, central, and southwest locations were $\approx 402,162$, and $125 \mathrm{~h}$, respectively. percentage of fruit that exhibited flush tips was similar at all three locations tested and generally ranged from $40 \%$ to $70 \%$. The only cultivar to exhibit a significant difference between sites was 'TropicBeauty', which had a lower percentage of flush tips at the southwest location (Fig. 1). No significant differences among cultivars within locations were observed for the percent of fruit with flush tips with the exception of 'Flordaglo', which had a lower percentage of fruit with flush tips at both the central and north-central locations.

In contrast to the results for flush tips, differences among cultivars were observed for the frequency of recessed tips at all locations (Fig. 1). 'TropicBeauty' had the lowest percentage of fruit with this phenotype at all locations, although differences were not always significant for all cultivars at all sites. Within central Florida, the percentage of fruit with recessed tips for 'Flordaglo' was significantly higher than for
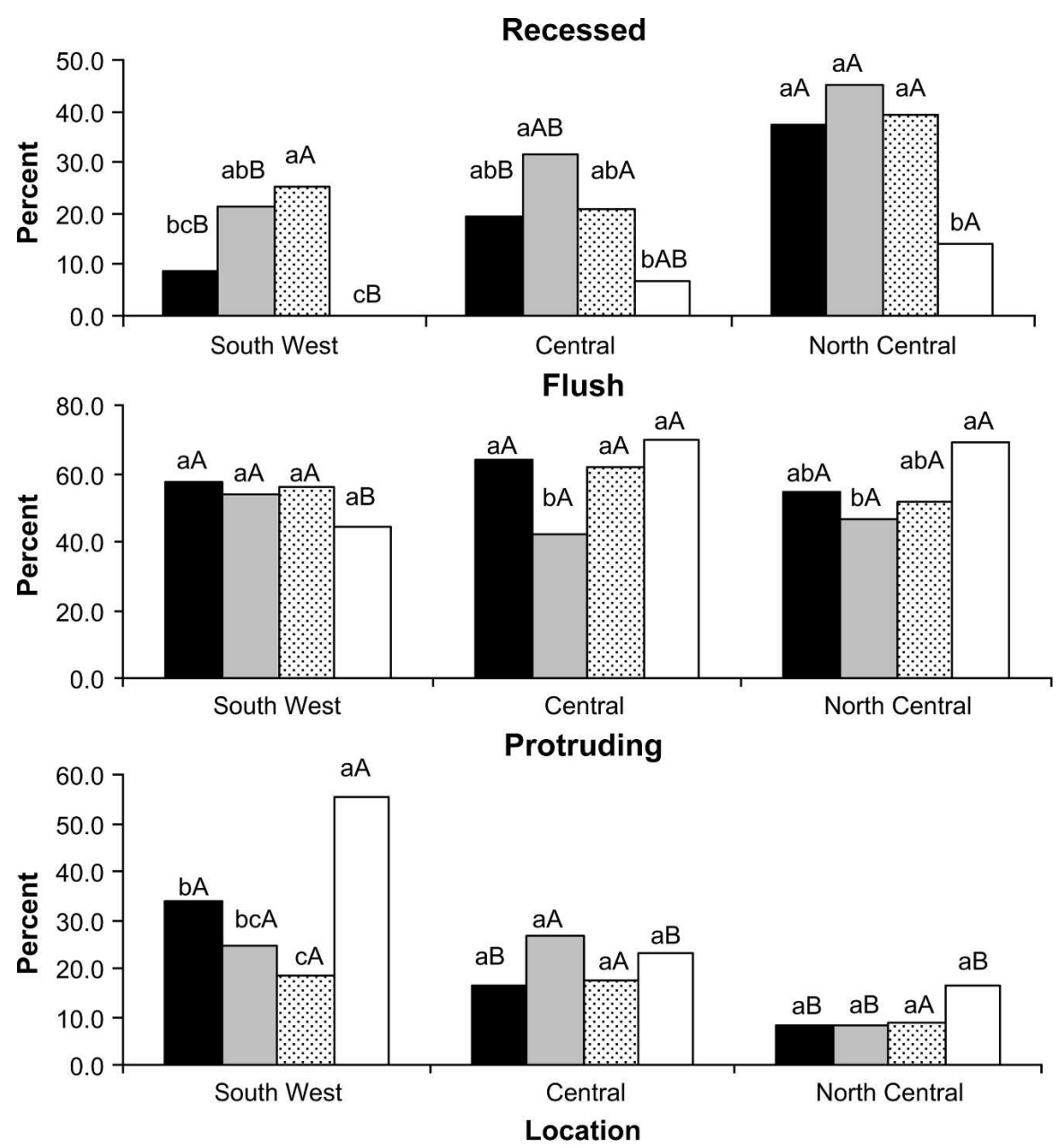

Flordaprince $\square$ Flordaglo $\mathrm{Q}$ UFgold $\square$ TropicBeauty

Fig. 1. Percentage of peach fruit with recessed, flush, and protruding tips within the north-central (NC), central (C), and southwest (SW) locations. Accumulated chilling by location was $400 \mathrm{cu}$ for northcentral, $162 \mathrm{cu}$ for central, and $130 \mathrm{cu}$ for southwest. Lower case letters represent significant differences among cultivars for a certain trait within a location according to Tukey's test $(P \leq 0.05)$. Uppercase letters represent significant differences among locations for a certain trait for each cultivar using Tukey's test $(P \leq 0.05)$.

'TropicBeauty'. The percentage of recessed tips for 'Flordaprince' and 'UFGold' were not significantly different from either 'Flordaglo' or 'TropicBeauty'. At the southwest location 'UFGold' had a higher percent of fruit with recessed tips than either 'Flordaprince' or 'TropicBeauty'. There was a trend for a reduction in the percentage of fruit that showed recessed tips as the locations progressed south for all cultivars.

The percentage of fruit having protruding tips ranged from $8.0 \%$ to $17 \%$ at the northcentral site and from $19 \%$ to $55 \%$ at the southwest site. There were no significant differences among cultivars for the percentage of fruit with protruding tips at either the north-central or central locations. However, at the southwest site, 'TropicBeauty' had the highest percentage of fruit with protruding tips. 'UFGold' had the lowest percentage of fruit with protruding tips, being significantly lower than 'TropicBeauty' and 'Flordaprince' but not 'Flordaglo'. Overall, the north-central location had the lowest percent of fruit with protruding tips for all cultivars, and there was a trend for higher percentages of protruding tips as the locations progressed south.

Temperature differences among the locations during fruit development may be the primary cause of the differences observed in the percentages of fruit with recessed and protruding tips. Regression of the percentage recessed and protruding tips on the mean maximum temperatures 4 weeks after full bloom resulted in linear equations with high $\mathrm{r}^{2}$ values (Figs. 2 and 3) except for 'UFGold', which was not as strongly affected by mean maximum temperatures as were the other three cultivars. Flower and fruit development in peach is not completely synchronized under subtropical growing conditions. The bloom period typically lasts several weeks. It is possible that the recessed, flush, and protruding tips represent fruit produced by precocious, mid, and late developing flowers, respectively. Early-developing fruit could be exposed to lower temperatures leading to recessed tips, whereas late fruit would be exposed to higher temperatures leading to protruding tips.

Significant differences in suture deformation among cultivars and locations were detected by calculating suture deformation indices (Table 2). Suture deformation indices ranged from 1.05 at the southwest location to 0.95 at the central location. 'Flordaglo' had the largest mean deformation followed by 'TropicBeauty', 'Flordaprince', and 'UFGold'. The magnitude of the differences between cultivars was small compared with the differences among locations.

Peaches with protruding tips have been reported by various authors (Salvador et al., 1998; Topp and Sherman, 1989). The significant location effects detected in our results are similar to those reported by Topp and Sherman (1989) for 22 peach and nectarine cultivars evaluated at 13 sites in Australia. The cultivar Flordaprince was common to both experiments. The fruit was rated on a 1 


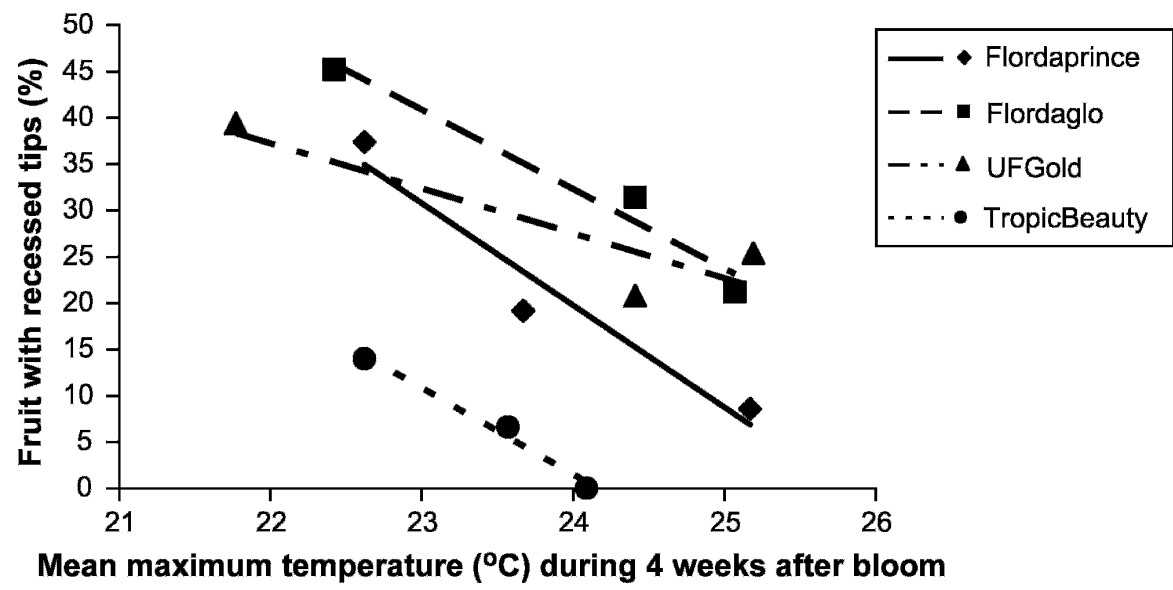

Fig. 2. The relationship between mean maximum temperature during the 4-week period after bloom and the percentage of fruit with recessed tips for four low-chill peach cultivars. Regression equations are: 'Flordaprince' $\mathrm{y}=-11.01 \mathrm{x}+283.9, \mathrm{r}^{2}=0.71$; 'Flordaglo' $\mathrm{y}=-8.56 \mathrm{x}+237.9, \mathrm{r}^{2}=0.61$; 'UFGold' $\mathrm{y}=-5.25 \mathrm{x}+152.1, \mathrm{r}^{2}=0.29$; 'TropicBeauty' $\mathrm{y}=-9.31 \mathrm{x}+225.0, \mathrm{r}^{2}=0.69$. Each data point represents the mean of five values $(n=15)$.

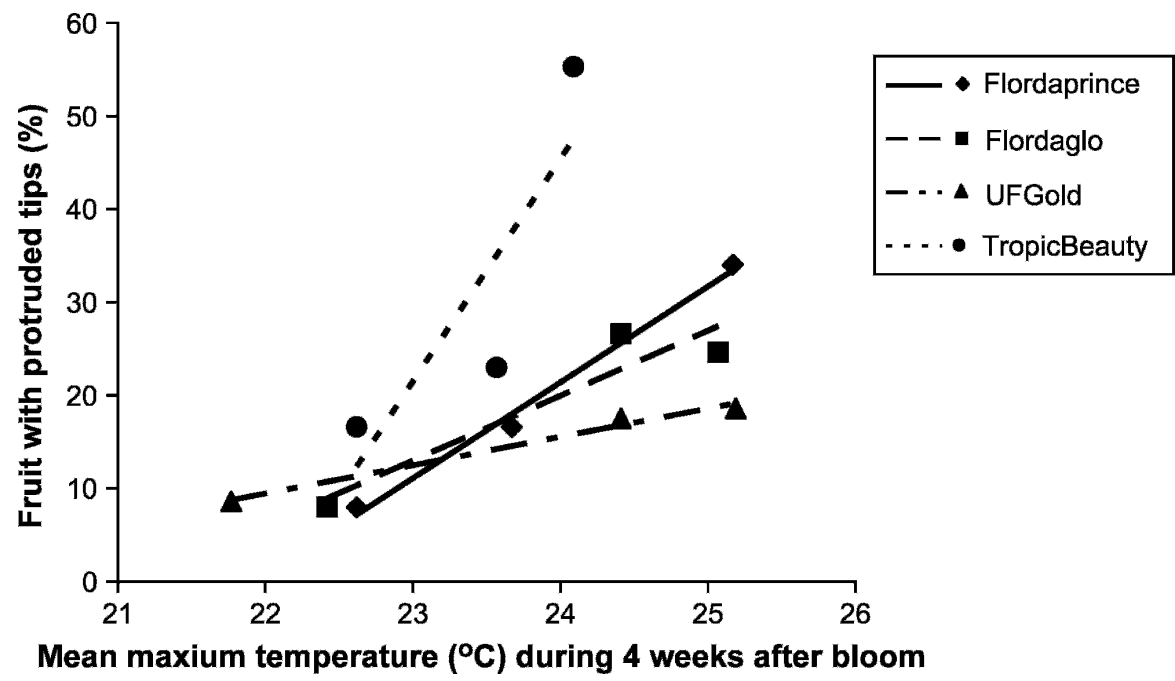

Fig. 3. The relationship between mean maximum temperature during the 4-week period after bloom and the percentage of fruit with protruding tips for four low-chill peach cultivars. Regression equations are: 'Flordaprince' $\mathrm{y}=10.29 \mathrm{x}-255.6, \mathrm{r}^{2}=0.78$; 'Flordaglo' $\mathrm{y}=6.978 \mathrm{x}-1.47 .5, \mathrm{r}^{2}=0.54$; 'UFGold' $\mathrm{y}=$ $2.70 \mathrm{x}-50.5, \mathrm{r}^{2}=0.22$; 'TropicBeauty' $\mathrm{y}=20.8 \mathrm{x}-456.5, \mathrm{r}^{2}=0.55$. Each data point represents the mean of five values $(n=15)$.

Table 2. Suture deformation (suture diameter/ cheek diameter) among three locations in Florida for four low-chill peach cultivars.

\begin{tabular}{lc}
\hline & Suture deformation index \\
\hline Location & $0.966 \mathrm{~b}^{\mathrm{z}}$ \\
North-central & $0.947 \mathrm{c}$ \\
Central & $1.051 \mathrm{a}$ \\
Southwest & \\
Cultivar & $0.985 \mathrm{bc}$ \\
Flordaprince & $0.995 \mathrm{a}$ \\
Flordaglo & $0.982 \mathrm{c}$ \\
UFGold & $0.993 \mathrm{ab}$ \\
TropicBeauty &
\end{tabular}

${ }^{\mathrm{z}}$ Lowercase letters represent significant differences among locations or cultivars according to Tukey's test $(P \leq 0.05)$ to 5 (protruding-recessed) scale. Regression of the stylar tip (extended blossom end) scale on temperature was found to be significant with an $r$ value of -0.65 . They found that most peach cultivars responded to higher mean daily temperatures during the coldest month of the year by increasing the frequency of protruding tips. Similarly, the frequency of recessed tips increased in most varieties when they were grown in climates with colder average temperatures during the coldest month. The lower $\mathrm{r}^{2}$ obtained by Topp and Sherman (1989) may have resulted from the subjective rating scale used to evaluate blossom ends. Protruding tip development has also been attributed to inadequate chilling or prolonged dormancy (Byrne and Bacon, 1992; Campbell et al., 1995; Koffmann and Patten, 1992; Rouse and Sherman, 1989, 2002).

Protruding tips and sutures can be bruised during harvest and shipping of fruit and are therefore undesirable traits for commercial peaches. Cultivar differences for fruit deformation were detected in our experiment. These results indicate that genetically superior germplasm such as 'UFGold' having both a low percentage of protruding tips and low suture deformation (0.93 to 1.04) and a low sensitivity to temperature effects exists. The results also emphasize the need for thorough testing of cultivars and advanced breeding lines in diverse climates.

\section{Literature Cited}

Aloni, B., E. Pressman, and L. Karni. 1999. The effect of fruit load, defoliation and night temperature on the morphology of pepper flowers and on fruit shape. Ann. Bot. (Lond.) 83:529-534.

Byrne, D.H. and T.A. Bacon. 1992. Chilling accumulation: Its importance and estimation. Texas Horticulturist 18:5,8-9.

Campbell, J.A., A.P. George, and R.J. Nissen 1995. An overview of the Australian low-chill stonefruit industry. Acta Hort. 409:47-66.

Koffmann, W. and A.R. Patten. 1992. Assessment of low chill peach and nectarine cultivars in the central coast of New South Wales, Australia. Fruit Varieties Journal 46:119-124.

Nauer, E.M., J.H. Goodale, L.L. Summers, and W. Reuther. 1972. Climate effects on navel oranges. Citrograph 58:51,54-55.

Nauer, E.M., J.H. Goodale, L.L. Summers, and W. Reuther. 1974. Climate effects on mandarins and Valencia oranges. California Agriculture 28:8-10.

Nauer, E.M., J.H. Goodale, L.L. Summers, and W. Reuther. 1975. Climate effects on grapefruit and lemons. California Agr. 29:8-10.

Rouse, R.E. and W.B. Sherman. 1989. Low-chill peaches in south Texas and potential in central Florida. Proc. Fla. State Hort. Soc. 102:193195.

Rouse, R.E. and W.B. Sherman. 2002. Peaches for subtropical south Florida. J. Amer. Pomological Soc. 56:179-184.

Rylski, I. and M. Spigelman. 1982. Effects of different diurnal temperature combinations of fruit set of sweet pepper. Scientia Hort 17:101-106.

Salvador, M.E., L.A. Lizana, L.E. Luchsinger, E. Alonso, and E. Loyola. 1998. Locality effect on some fruit quality parameters in peaches and nectarines. Acta Hort. 465:447-454.

Sherman, W.B., T.G. Beckman, and J. Janick. 2003. Climatic adaptation in fruit crops. Acta Hort. 622:411-428.

Topp, B.L. and W.B. Sherman. 1989. Location influences on fruit traits of low-chill peaches in Australia. Proc. Fla. State Hort. Soc. 102:195199

Wutscher, H.K. 1976. Influence of night temperature and daylength on fruit shape of grapefruit J. Amer. Soc. Hort. Sci. 101:573-575. 